\title{
DERECHO PROCESAL EN EL BALANCE A FIN DE SIGLO
}

\author{
Augusto Mario Morello
}

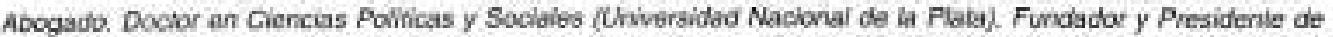

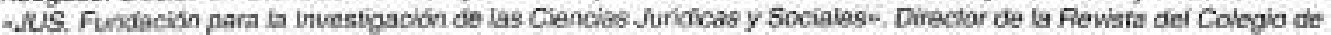
Abogados de in Plata. Findador y Director de vlus, Fievista Nuidica de ti Prowincia de Buenas Airese, 1962.

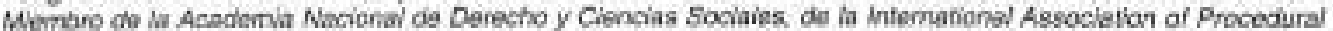

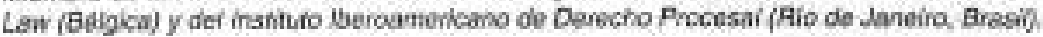

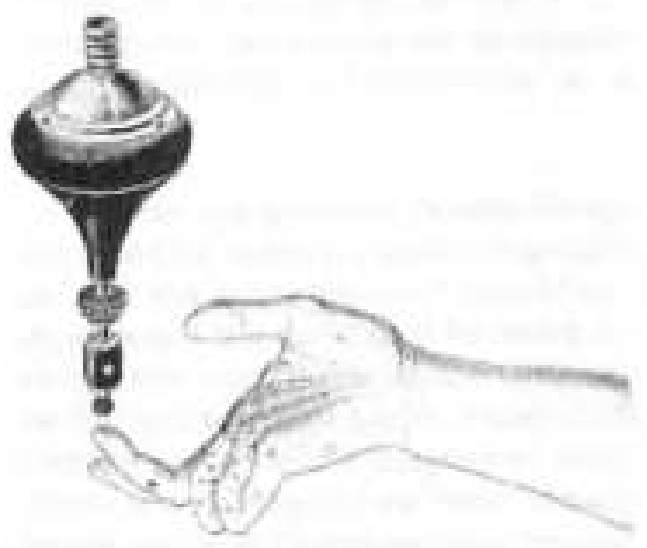

I. LOS GRANDES TEMAS Y SUS ADAPTACIONES EN LA HORA ACTUAL.

A I finalizar la década de los "BO, el paisaje del proceso civil se dibuja con estas notas distintas ${ }^{10}$ :

a) El Juoz, a su tarea normal -de dar so-

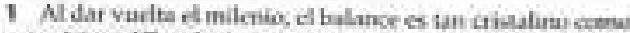

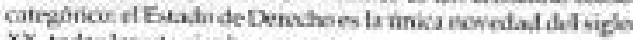
$\mathrm{XX}$, todas las atopias tam mivoria.

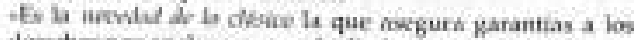

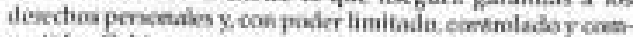

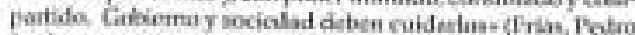

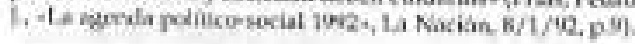

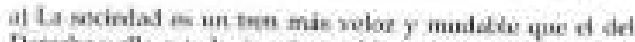

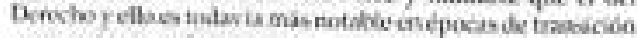

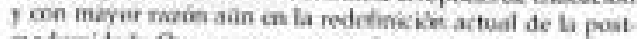

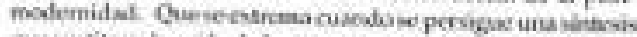

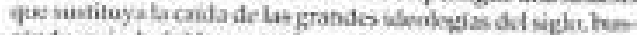

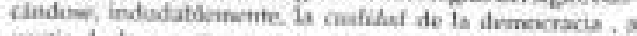
pirtir de la prusta en antes registros de has postutades

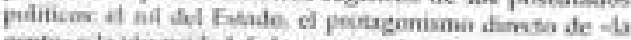

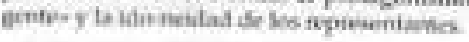

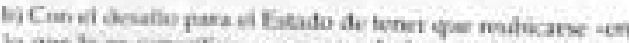

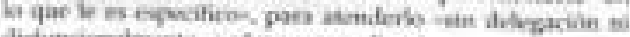

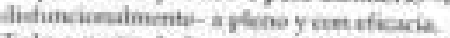

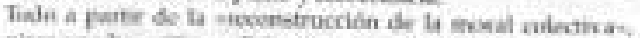

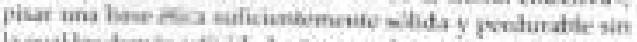

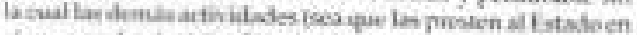

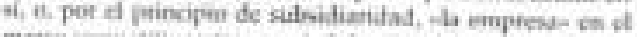

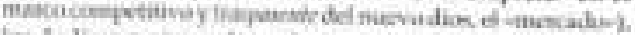

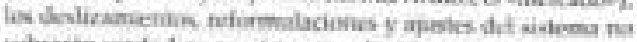

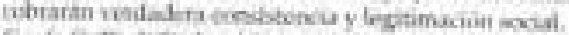

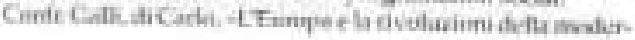


fuciones juridicas a casos concretos-suma una función creativa y un activismo protagónico; es decir, una presencia lúcida y concurrente dentro del marco de la responsabilidad social.

b) Desde los años sesenta emerge, universalmente, una delicada misión dentro del equilibrio de los Poderes del Estado de Derecho democrático: la de ejercer el control judicial de la constitucionalidad de la ley a ia luz de una norma superior (la Constitución) o -indirectamente-, como consecuencia de la controntación con las del Pacto de San José de Costa Rica, verificar el carácter constitucional o supranacional de estas últimas que pueden llevarlo a dejar sin efecto -inaplicadas aunque no declaren inconstitucionalidades-las normas interiores.

\section{c) El acceso a la Justicia y a ta efectividad} de la tutela jurisdiccional-tema fundamentalse abre prioritariamente en un amplio y sugerente abanico, abarcador de múltiples tacetas.

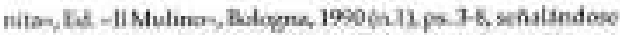

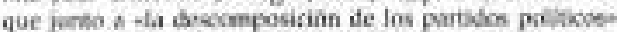

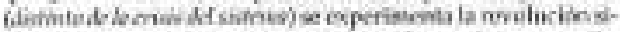

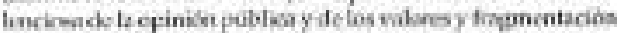

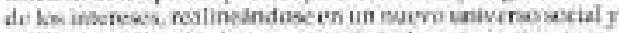

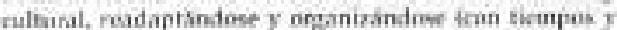

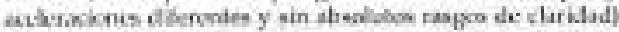

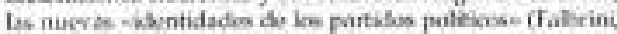

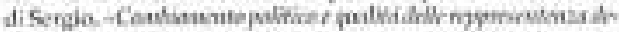

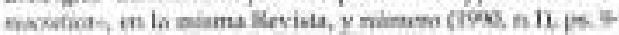
He laciadep (7):

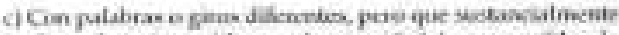

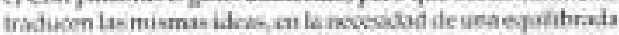

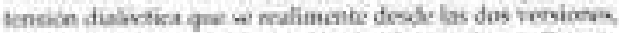

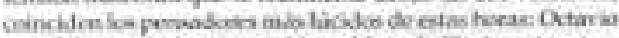
Faz Sahubs MLariab, Varges thro Massuh, Foria, antre otros

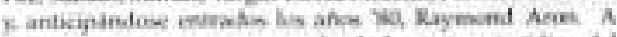

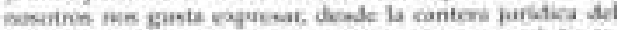

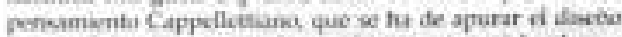

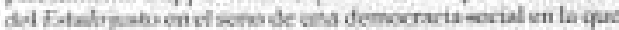

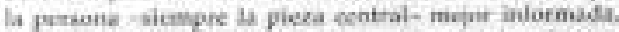

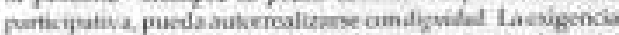

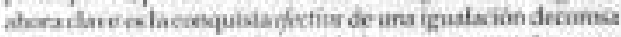

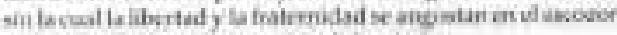

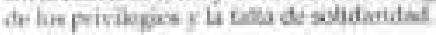

1) La cuestión básica de la legitimación de obrar -standing que ensancha la calidad, (y capacidad) de quienes pueden proponer pretensiones.

2) La igualdad real en las posibilidades y en el tratamiento, que agudiza la necesidad de derribar los obstaculos interiores y extemos (a las partes) en el proceso.

Queremos destacar, a poder proponer y defenderse eficazmente y sobre todo de manera efectiva, no sólo nominal ni aparentemente igualitaria (vor infra cap. III).

\section{3) La reformulación del debido proceso legal} adjetivo (a):

- por los carriles de la bitateralidad, aunque ella se materialice en un momento posterior a la resolución judicial, cuando razones de urgencia o de interés general asi lo aconsejen.

- por eficacia -utilidad en concreto. de la garantia técnica de excelencia fel aporte del abogado).

- por la ayuda legal (la potenciación hacia la igualación de trato real) en la ecuación económica del litigio: que el costo no sea fuente de privación de fusticia, desde un

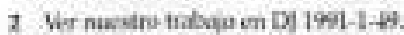

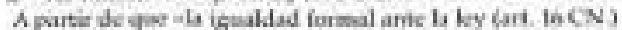

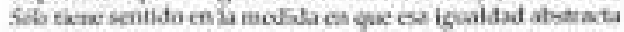
in quede destrozada socialmcnite por ba desigualdad maknal

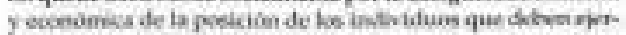

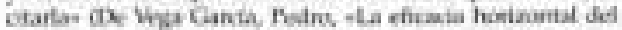

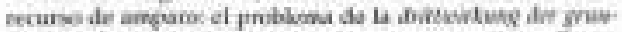

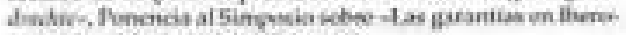

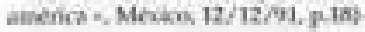

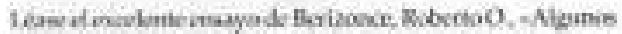

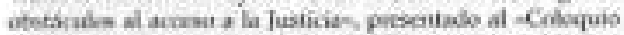

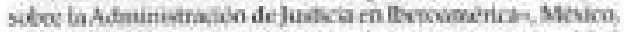

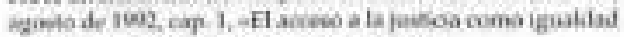

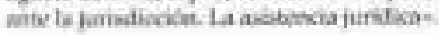


mirador modemoly,

- por la adaptación del trámite de protecoión del "derechon subjetivo clásico a los nuevos "derechos" ciertos liquidos (más que de intereses legitimas) de caracter colectivo y dimension social (del litis consorcio circunscripto al Mis consorcio mulbitudinario abierto). Compromiso maleable del Servicio con situaciones grupales (categorias, clases), homogeneas, destinadas a la pro. tección del medio (hábitat) y de los consumidores (latu sensu). De los mecanismos procesales singulares (pensados para e: conflicto individual entre Cayo y Tizio, en relaciones básicamente estáticas, consumadas en el pasado), a otra indole de conflictos de masa que se mantendrán en tensión hecis adelante. Presididas por la cooperación, colaboración y soúdarismo, en el juego funcional (instrumental) de derechos en colisión a los que hay que graduar -la libertad ordenada-, La armonización de las

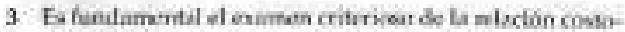

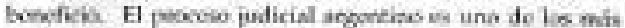

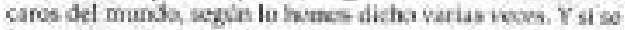
lo comi-nia presionando con el castigo de lin pashes tasas.

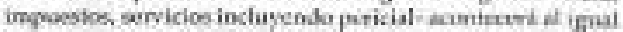

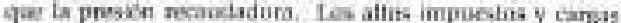

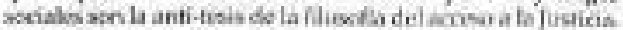

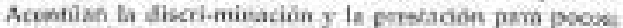

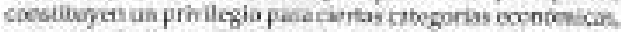
Iraicionando 4 isoalaivin pre el elitismo con to cual bos

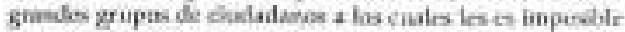

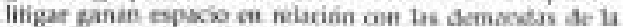

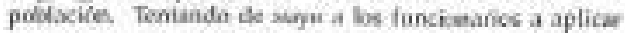

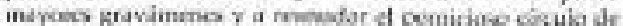

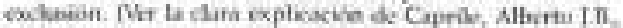

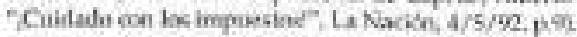

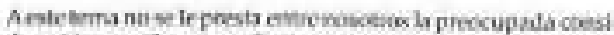

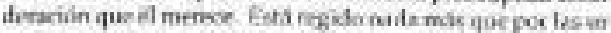
entrias fiksire.

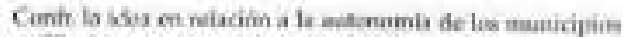

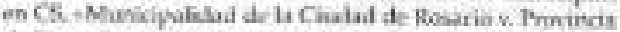

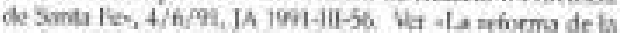

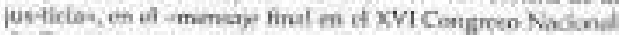

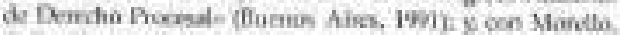

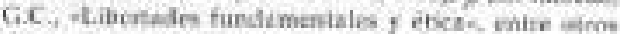
dosirmais avirishs «pequeñas-grandes libertades» que de no ser protegidas comprometerian la dignidad del hombre en la aitura alcanzada por las sociedades capitalistas maduras y, además, la calidad de vida.

- porque son cada vez más manifiestos los rasgos que evidencian la crisis de la estructura rigida con pretendidos caracteres uniformes y generales de la práctica del contradictorio (partes-juez) (Adversarial proceounings).

- por la impronta y delicada tarea de la inter. pretación gobernada por el principio finalista (art. 24 Codigo Procesal Modelo para Latincamérica).

\section{"Según sea la concepción *liberal politica también será la concepción liberal del pro- ceso ".}

- por una visión histórico-politico-comparatista y contextual; sobremanera, una inteligente actitud cognoscitiva para ceptar los problemas desde la optica del estado de Derecho moderno en la dificil tendencia de una sintesis iberai-solidarista.

Seguin sea la concepción - fiberalo politica -de impronta social-también sera la concepción liberal del proceso. Empresa privada, propiedad, capitalismo liberal y la idea central de mercado, no pueden escaparse de esa pauta guits.

Ei significado do Pberai en Cappelletti, apunta Eduardo Ricci, debe ser el de la batalla de la Ibertad; entendida en el derecho social de la libertad más que el derecho tradicional o del 
primer plano de liberalismo procesal clá-sico.

- por el tratamiento interdisciplinario de los problemas signados, mayoritariamente, por su dimensión social.

- por la conveniencia del método de investigación empirica como instrumento de análisis de la realidad ivi; la experiencia concreta, las necesidades vivas, en el espejo del derecho comparado. Reparando en lo decisivo de los hechcs y particularidades con que se construye el caso a través de un recorrido analitico y de verificación práctica que no se desvirtúe por apego a la lógica deductiva, a lo abstracto y general de las normas junidicas o la explicación conceptualista.

\section{- en la comprensión de que no cabe sacrificar} la solución del compromiso - to posible-a una idealización imposible por excesivamente teórica, abstracta, antieconómica, al cabo impracticable.

Según Poincare, los cientificos de la naturaleza discuten sus resuitados, mientras que los cientiticos sociales discuten sus métodos. Acaso en este esfuerzo de alcanzar un

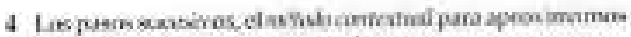
engeveral a balis les iemas son bolite

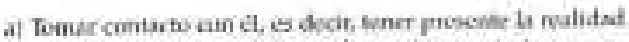

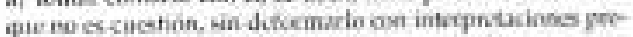
vias

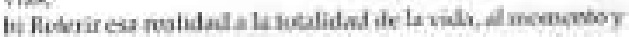

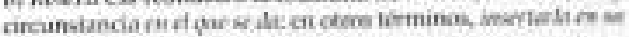

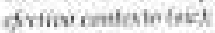

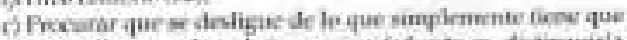

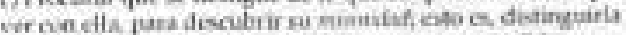

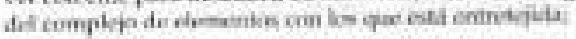

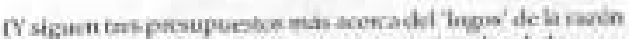

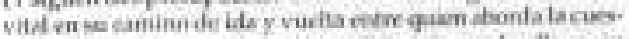

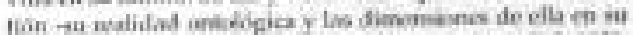

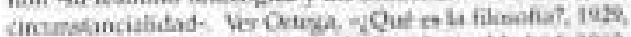

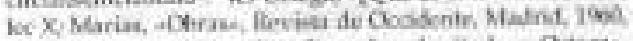

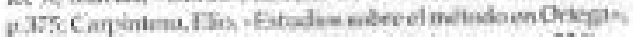

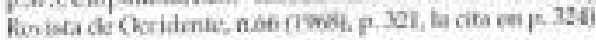

realismo cierto en la investigación de los problemas tomándoles en vivo y tales como son en la manilestación construida y probada en el procesode que se trate y en el logro de respuestas efectivas se reduzca ol -derroche teórico", y la fuga hacia el =derechon que daria sin más la respuesta única y generai, habida cuenta que las expresiones doctrinarias y la profundización de los lemas sólo pueden desarrollarse en el proceso de intentar explicar la realidad (s). El con-

5 Hall, fohn = Voderesy libertadese, trot de Hernin Sabate.

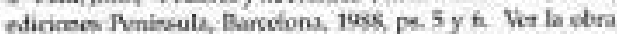
-Dercchay rovialadn Academia Nadonal de Desshan Cien das Socbles dit Burvis Ains. 1990

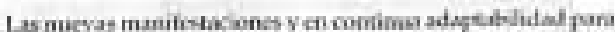
abastuocr ua blanco movil crazalo por myacrimiontos y

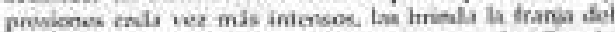

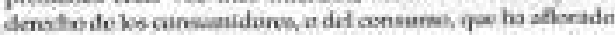

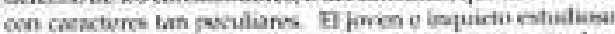

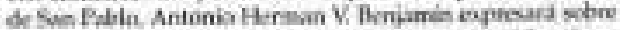
el particular que el mescado modoma - qee ievenaficaed vas

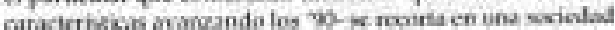
amprocanal, masificada y aen ansnimatos. Que son rotabko Li newva relaciones juridleas, coneso of impreto de la

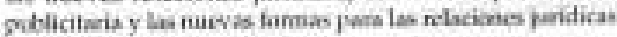
inationalis tiamyervental.

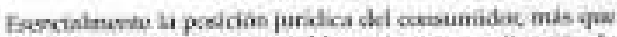

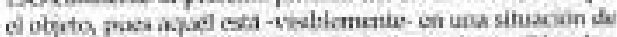

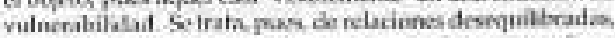

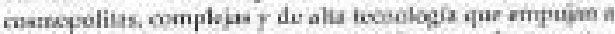

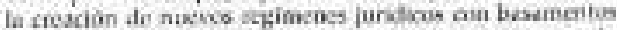

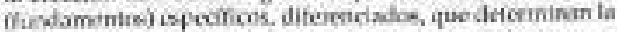

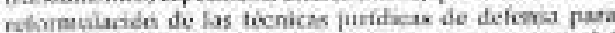

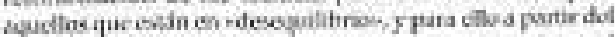
fompertamirnia activo de is Administrasibe fuctie cuntrol

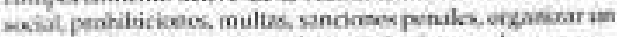

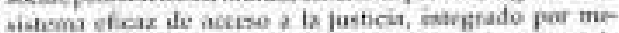

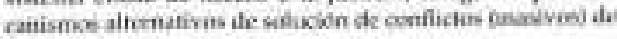
cussuming

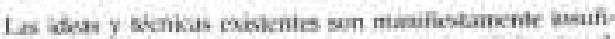

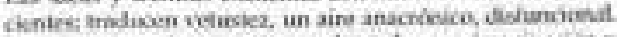

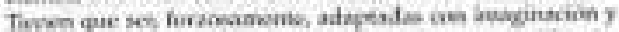

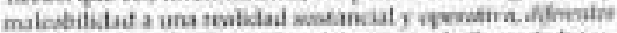

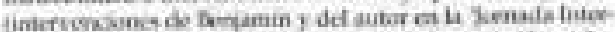

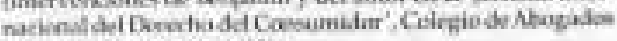

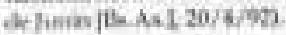

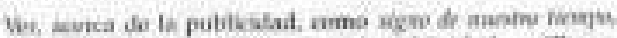

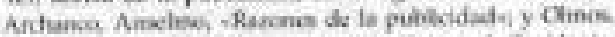

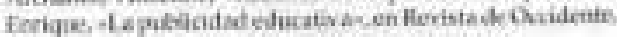

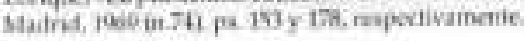


centrarse en ellos permite resultados

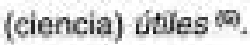

4) En la sintesis; apuntara con inteligencia Barbosa Moreira, un fuerte cariz de proposiciones de transformación o adaptación. De redefiniciones o, como nos gusta acotar (siguiendo a Lain Entraigo) de usar lo que existe de ofro modo, aceptando el cambio de tomas, que consiste en el pasaje:

medio ambiente y las intereses *ditusos y colectivos*. La tutela de la sociedad, de mi circunstancia, sin cuya incolumnidad el yo de esa circunstancia no tiene porvenir (incluyendo la reconstrucción de la ética $-\mathrm{Ca}$ ppelletti-

- En la frontal lucha por la igualación de posibilidades, de acceso a la cultura (a mejorarse espiritual y culturalmente) a la salud; a ser autónomamente pleno.

- de lo simple a lo complejo,

- de la nacional a lo trasnacional,

- de lo individual a lo social(Barbosa Moreira),

5) Aflora, entonces, el otro horizonte:

- Los problemas

“... las "grandes y graves. cuestiones de la sociedad, a las que el Derecho Procesal debe suministrar efectiva y funcional cobertura de aseguramiento, pacificación y realización material bajo el farol de la Constitución ". biobticos; la armoni-

zación de las pequeñas grandes liborlades en las tensiones de la tutela del derecho a la intimidad, los derechos al aborto, a morir con dignidad, a la calidad de vida, el respeto de las minorias, los inmigrantes, el derecho a la paz, a no ser discriminados, ni apartados- a no ser desaparecidos o forturados, elcetera.

- A la protección cada vez más enérgica del

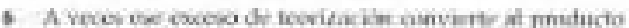

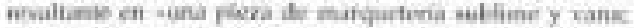

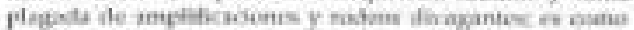

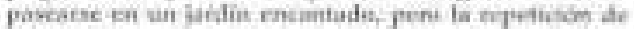

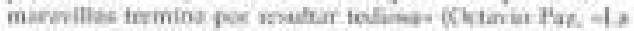

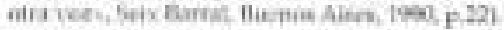

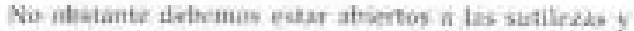

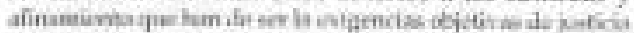

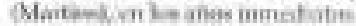

- Y a acorralar a la pobreza, madre de la mayoria de los intortunios que opacan el acceso a la felicidad. segùn los patrones eticos y equitativos que impone la pauta de la solidaridad social.

Sin olvidar enel siglo de la inteligencia -al que nos aproximamos-, ni la compelencia feroz y la esforzada superación en pos de la excelencia.

Por todos esos flancos discurrirán las *grandes y graves" cuestiones de la sociodad, a las que ol Derecho Procesal debe suministrar efectiva y funcional cobertura de aseguramiento, pacificación y realizazión marevias bajo el farol de la Constifución.

Computar -en dosis adecuada-estos decisivos datos de la realidad, en nuestra opinión enriquece la perspectiva juridica y refuerza con autenticidad los fundamentos cientificos propios de nuestra área del Derecho. Sienciarios o dejar do acordarles el relieve que ellos tienen pecaria, por el contrario, en disfavor de las posibilidades propias del Derecho Procesal, lafu sensta 
6) En tin, la clave de una soldadura equilibrada entre pensamiento odogmático", descarnando la trama real y vigente de las normas, los grandes principios y la inyección de una dosis socioldigica -ol ahora y aqui-con sentido de politica juridica conveniente y razonable; que no desoye la lógica interior de las fenómenos económicos y de otra indole que se aiojan en las cuestiones juridicas, las presiones -los ruidos y ondas- de la sociedad, conjugados equilibradamente con la optica del derecho y sostenido el conjunto por una solida base ética, es decir, apoyada en compactados cimientos morales.

\section{DESARROLLOS.}

No se escapa que el rosario de factores y guias asi enlazados roconoce como punto de partida un entoque de caraicter didactico con una visión teleológica o finalista del Derechom.

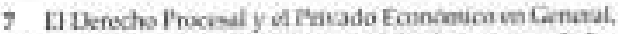

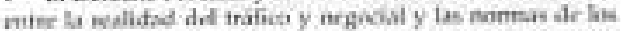

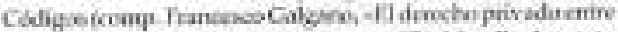

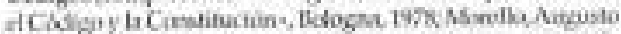

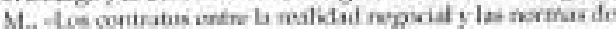

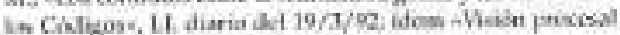

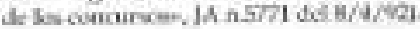

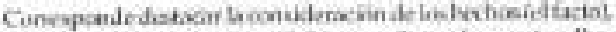

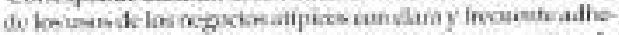

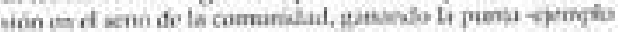

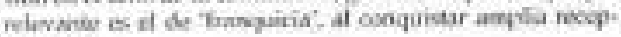
tibiliand

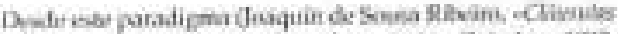

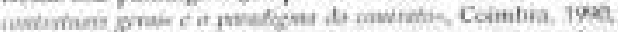

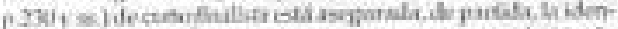

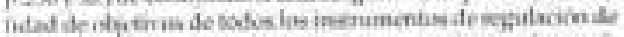

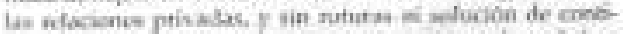

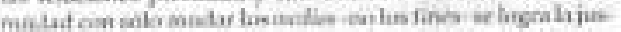
tios emonanias!

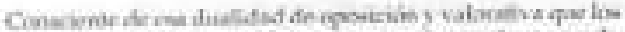

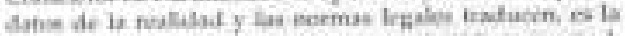

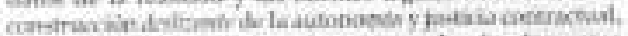

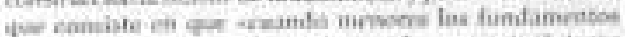

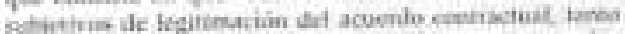

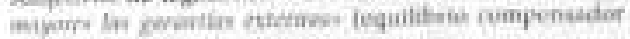
diahnimp
Veamos, desde laderas "calientes" (vivas y en desplazamiento) cömo se van trasformando las instituciones en una evolucioin y ajuste cuyas notas se iran pertilando con mayor nitidez en los anos finales de la centuria.

\section{a) Crisis del processo.}

- en el eje del "sistema aoversanialo o de contradioción que hay que reconducit con las altemativas de la conciliación (el diálogo, la persuasión, la disuación del litigio) y el arbitraje (retorno a la justicia privada).

- el debate sobre la reforma del proceso civi (costoso, frustratorio $\theta$ intolerablemente largo), demanda concretar otra cosa, hacer algo.

- desde Chiovenda (postguerra de 1920) la idea central es la de la oralidad; recepción en temminos relativas pero tecnicamente a pleno. La oralidad, y la relatividad de prin. cipios que se entrecruzan y enlazan en realimentación continua, que se corporiza en la dirección del juez; el acogimiento de la conciliación o del arbitraje no son de implantación general para todo uso; sivven. son idoneos -utities- para clertos litigics; no lo sco, en cambio, para otros. Esos tratamientos procesales diversificados. en corres. pondencia con la complejidad, cienticidad y complicación det cojeto y del tramite del litigio, se adaptan mejor y sin costos adicionales, al prescindir de imponer un modelo único, unilorme y rigido. Ello se vuelve contra la bondad tebrica de los principios, al querer 
-encapucharw cerradamente zonas o controversias mejor tratables, en la experiencia viva y del desarrollo procedimental, por ef juego y teicnica que corresponden al otro ( $u$ otras) modelo Creemos que sólo tiene predica. mento general el principio de inmediacidn, que es indicado para todos tos jueces y en los puntos o momentos claves de su progresión. El, si debe cobrar clara vigencia; los demás pueden (comviene que sea asi) elastizarse o acomodarse con inteligente dosis $y$ diferencias cperativas, entre el juez y las partes, a contar (Vargas Llosa) de que ser imparcial no es ser indiferente. Yel juez está ajeno y distante, el resultado final dejará inconforme al Servicio y a su finalidad.

- Cooperar sogún fos distintos roles, con sustento en el principio cardinal de la solidaridad $y$ on que son deberes de la persona y del ciudadano, no sólo de los sujetos de éste $y$ aquel proceso en particular, colaborar para el buen funcionamiento -y agregamos para la obtención de resultados elicaces justos. de la Administración de Justicia lart. 95, lite. ral 7 de la Constitución Politica de Colombia de 1991) it.

- A esos fines correspondo repensar la interdependencia y organización de la disputa y debate judicial:

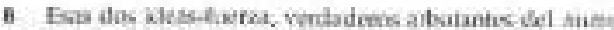

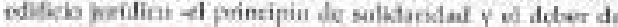

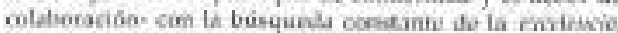
susfentado el cociunto at una rocienstruceike de la ético

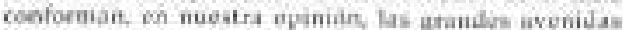

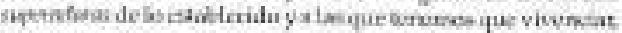

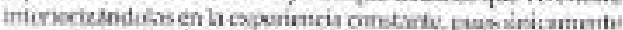

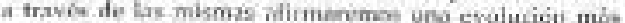

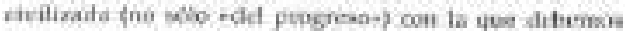
imumir on el meco milatis (Mrrella Aususdu MNin y

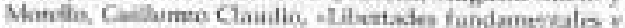

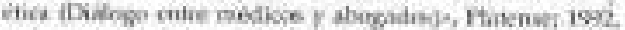

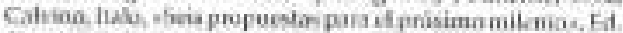
Growle,ichis nasions

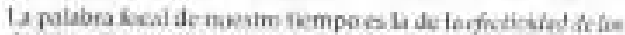

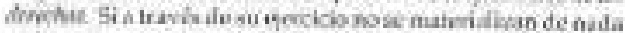
valtn. De alli la importancia de les gemantiss $\mathrm{V}$ de $\mathrm{m}$ oporativilait sev'
- reformulación del principio del debido proceso legal, proceso monitoria, réfévé, procoso de urgencia, modidas cautelares, alteración o posposición de fases estructurales, sin que en la sumatoria se lesione la garantia constitucionat de la debida audiencia. Cabe apuntar que las grandes corrientes o innovaciones de la realidad litigiosa -por causas económicas y sociales- obligan a replanteos de hecho (todavia no recogidos en los textos legales) pues -y solo es uno de los ejemplos- la admisión de medidas cautelares y procesos urgentes revisten importancia de por si decisiva. Mas que al servicio de una emanación jurisdiocional ulterior, el decreto de una prohibición de innovar, en determinados supuestos, por sus consecuencias bloqueadoras y de gravitación económica, es ya equivalente a las consecuencias que produciria la sentencia en el mérito. De alli que: según las particularidades de caca caso, el alzamiento -aun ante la Corte Federal-se hace de proposición ineludible, pese a la conocida doctrina que explica -en la teoria general- que esas resoluciones, por via de principio, no son definitivas y por tal (además de su carácter procesal) son ajenas al recurso extraordinario.

- Nada es simple, lineal y absoluto en el Derecho an su totalidad y con rasgos más scentuados (y cinámicos) en el procesal.

Determinar por consiguiente, cuáles deberian ser los contenidos tiquidos y genuinos de los conflictos estrictamente judiciales, tal como insistentemente venimos señalando en los últimos años, se levanta como tares previa para la elaboración responsable de cualquier politica de Roforma de la Justicia. para preser presupuestariamente el cardinal aspecto de la relación costo-beneficio y racionalizar la financiación de un Servicio Fundamental, que aparece notoriamente debilitado en sua posibilidades técnico fun- 
cionaies especificas. (Ver intra, cap.III). Será un reto inevitable de los años inmediatos.

\section{b) Efectividad de la Jurisdicción.}

- Moderna tecnología lógica y adecuada fa. cilitación de la realización -no frustración- de los "derechos".

- Estructura judicial funcionat: dembar las bameras y cbstáculos impedientes de las garanfias, kas restricciones o discriminaciones que son los verdaderos obstáculos o vallas al acceso real a la jurisdicción.

- Supresión de los largos aperiodos muertos. del proceso, erradicando del Tribunal itigios inuties $\mathrm{y}$ las mallas incidentales interiores retarcatarias o parásitas, porque se ignoran las reales causas de esas fracturas;

- Medidas cautelares que son de decisión anticipadas y que valen por si mismas, que resuetven el conflicto sin quedar pendientes - subordinadas a la decisión ulterior de un proceso que ya no interesa agotar ni componet.

Nos parece que sera clave el reterido repertorio, eje referencial sugerente y abarcador. El mas movido de los campos de incidencias, donde el Derecho Procesal (y Procesal Constitucional, en purticularporque se acopla a la red de las garantias) habrá de desplegar su cooperación y técrica instrumental de servicio.

- La seguridad juridica deseada (también posible) igualmente sará cada vez más dinamica y llevible, dándose prioridad al interés social o goneral sobre el particular.

- Por ciento que ase empeño de iguaiación real no seria una utopia fuera de moda.

Dosmontar una a una (en un proceso desdichadamente de largo aliento, pero que no debe postergarse ni hacer menguar los eitusiasmos ni las illusiones; las diversas resfricciones, imposiciones y obstáculos existentes (o a emerger por la propia dinamica de los intereses sociales) es una tarea impro- be aunque crucial para el porvenir y consolidación de la Democracia. De lo contrario. esa -realidad- injusta y discriminatoria podria llegar a impedir el accero a la Justicia porque mediante las sucesivas $\mathrm{y}$ sofisticadas desiguaidades reales que irian serpenteando entre el privilegio de un lado y la pareja indetensión cierta en la contrapartida, llevaria en ios hechos a desarticular las bases efectivas del proceso justo constitucionat.

- Véase -y obviamente que no son todos. cuántos interrogantes y desafios a la imaginación de propuestas razonables envuelven a los juristas y operadores protesionales del Derecho $m$.

c) Tendencias que muestran los valores $y$ metas a preferenciat.

- Hay sectores -como en el proceso civil (privado)- en los que en verdad ef contrato conserva su classica función de actuar en ta mediación juridica interpersonal, siendo la voluntad de las intervinientes, consecuontemente, el factor constitutivo y el fundamento de los efectos juridico-nogociales. Aquil se hace evidente que el instrumento contractuai representa, verdademamente, una delegación y una apelacián al poder jurigeno de is persona en la conformación de las relaciones.

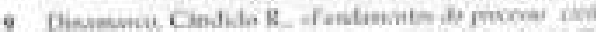

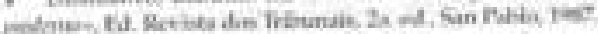

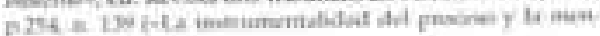
Elital dal pure-1

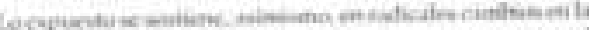

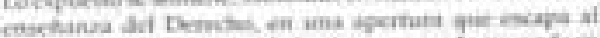

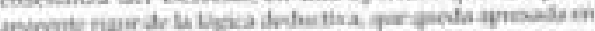

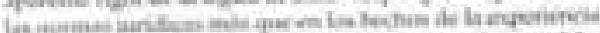

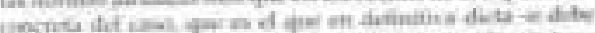

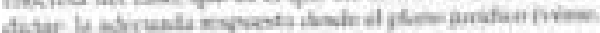

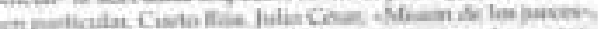

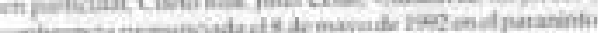

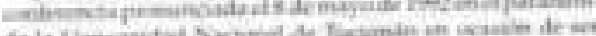

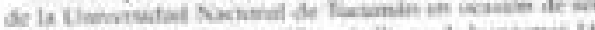

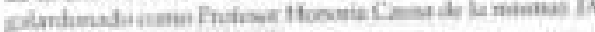

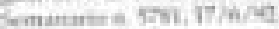


La composición heterogénea de la estructura social y las caracteristicas de los fenómenos abiertos y compleios del mercado, penetra en los planes y limites de la idea codificadora $y$ de su conveniencia y posibilidades en una época de transición.

Bastan esas referencias. De alli que, volvemos a puntualizarlo, en otra cuitura del proceso judicial y manera de ser do la controversia, ese método (nuevas opciones, otras alterna: tivas) mas humano y funcional, deberia recoger, cuanto menos, cuatro parámetros o referencias obligadas:

1) Mirar la realidad y no sólo la nuestra;

2) Relativizar las expectativas;

3) No dar, ni pratender perpetuar, respuestas muertas a problemas vivos;

4) No apagar las buenas ilusiones y utopias (10\%)

Por consiguiente, una comprension sistemática y contextual en la evolucion rapida de la totalidad de las estructuras sociales, económicas, politicas y culturales, permite avizorar que ambos derechos -civil y procesal-se ven enírentados a las realidades externas descritas, que lo sitian y condicionan. Son serkales

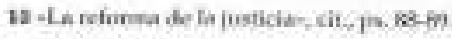

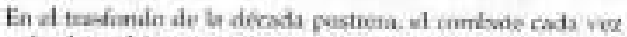

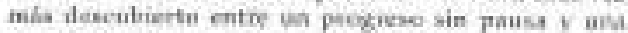

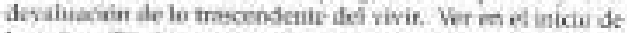

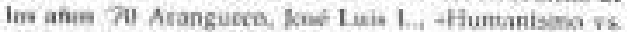

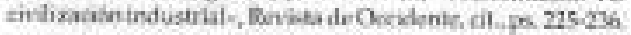

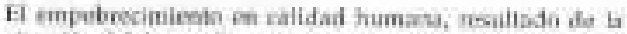

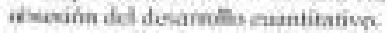

potencialmente reveladoras de que las teorias en uso, en uno y en otro cuadrante, cuanto menos son limitadas, o ineptas para dar cabal cuenta, con pertinencia, de ese ensanchado horizonte. Que le demanda lo establecido una distinta metodologia, más funcional y maleable; y que en la renovada motivación con que se ha de elaborar la tecria fundante, no se podrá dejar de sintonizar las exigencias del solidarismo social.

El derecho procesal se recrea con otro tipo de pensamiento, de fundamentos más realistas. Aflora preocupado y alento a los resultados valiosos, adosa. do a un accionar protagónico, principalmente de los jueces, también controlado y moderado; pero más auténtico, al sacudirse el peso encarcelador de las formas, dominado por una lógica opuesta a los conceptualismos y desgrillado de la ùnica finalidad técnica de los garantismos. Adscripción a un activismo prudente y lúcido. Exclusión de posiciones extremas, procurando asociar la libenad a la justicia contractual -a la dignidad intrinseca del negocio de cambio-. Para lo cual ha de establecer entre ambos, por canales, formas, mélodos, controles, un necesario sentido de equided, proscribiendo cualquier interprelación que desomboque en lo absurdo o irrazonable; cobijándcse para elio en pošticas "especiticas" y en una inteligente armonización-conexión entre el derecho londal y el instrumental de servicio.

El enfoque y tratamiento sistematico $19 \mathrm{se}$ lleva a cabo con mayor transparencia y buscando la operatividad de los derechos. Si 
ellos no son efectivos, es decir, si no cobran ejecu-ción puntual ¿para qué las garantias y los grandes enunciados -promesas- de los textos constitucionales?

\section{LA IDEA RECTORA DE LA SOLIDARIDAD DESDE LA PERS- PECTIVA DEL PROCESO SOCIAL DE DAÑOS}

Algo similar -con otra perspectiva pero cuajada de la idea de la solidaridad social-se experimenta en la estera de la responsa. bilidad civil, en el derecho de daños.

Baslará, en un boceto inacabado, recortar estas puntualizaciones, que intentan mostrat una linea de politica legislativa encaminada a impedir la proliferación de demandas (disuasión de los procesos).

a) Ambuito de la responsabilidad civil (daños en fa circulación).

- Accidentes de tránsito con daños en las cosas.

\section{- Accidentes con daños recaltuos morales corporales lesionod}

- Tratamiento díferenciado atendiendo a las consecuencias, a partir de una evidencia insoslayable: tos traumaticos trastomos socia-

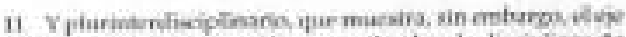

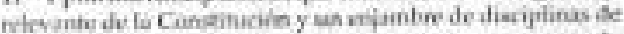
ferecha pubitico, de carrifes cuevergentes, que tae de

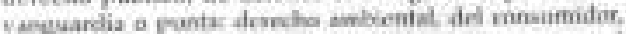

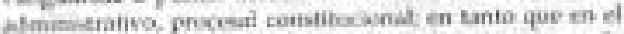

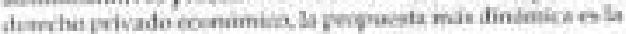
detilenstwo do be nopociets

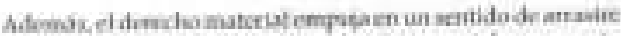

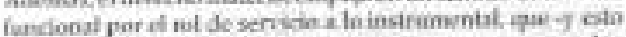
nu partce fimero- ha de farilitar y no enkorperer las

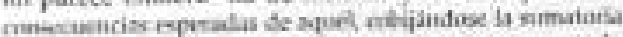
en le sumbrilia ate una. Constiturián interpretada

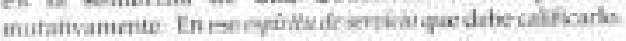

les y la contribución negativa a la sobrecarga que, en la experiencia contemporánea -en la Argentina y dentro de ells en la Cap. Fed. y en la provincla de Buenos Aires notoria. mente-están causando la proyección increscendo de los accidentes de tránsito *con victimas:; muchas de ellas fatales.

\section{b) Fines.}

- Facilitar la tutela y el cobro de la indemnizacion tarifada.

- Matiz esencialmente preventivo del corr. portamiento en el tránsito.

c) Cambio de mentafidad en el fenómeno de ios accidentes de tránsito.

- Una nueva cultura vial y de oamortiguación de conficictoss en la corrvivencia.

- Sanciones y premios por actos y omisiones de uprevención - y cortesía vial.

- Campaña informativa y de explicación (medios sociales, Colegios

Profesionales).

- Una educación solidarista desde la forma. ción primaria a la universitaria.

- Retiro y cancelación de las licencias de con. ducción.

La clave es cultural: informar y educar para hacer el buen cludadano.

d) Interés de la victima (consumidor del servicio)

- Reducción del mecanismo de determinación y documentación de:

a) daños;

b) cuantias:

c) pericias de valor suficiente, (acta cuantificante).

- Imversión de la carga de la prueba cuando hay negativa de acatamiento al procedimiento conciliatorio. 
-) Reducción de obstaculos Metodo por compensacion. Opciones decisivas para la -liquidación y yarificación de daños)

1) Aumento de la legitimidad de obrar. (Dilatación del acceso a la justicia)

2) Facilitación e induccion de tórmulas directas de solución:

- acta de verifica-

ción del daño y cuantificación.

- apoyo dal seguro obligatorio.

- conclifación estimulada

3) Tarifación y topes indemnizatorios.

4) Disminución del costo fiscal.

5) Techos y pisos del dano moral y su cuantificacion proporcional, con arreglo a pautas objetivas.

6) Reducción del rubro gastos causidecos y honorarios.

7) El incumplimiento y cualquier posición abusiva genera, automaticamente, imposición de astreintes, quedando equiparado di rotardo o el incumplimiento judicial al mismo tratamiento que el del evasor impositivo.

8) Publicidad (similar a la que se dispone por la D.G I con los nombres de los mayores contribuyentes), dentro de las horas, de las Compañias de Seguros que no depositon ol importe liquidado de ta condena dentro del plazo legal y do transcurso automático.

9) Creación del ombusman de comportamiento vial y a cargo del seguimiento de la ejecuidon de los responsables (condenados) en el cumplimiento de las conderias.

10) Control de estadisticas, memoria y proposición de mejoras en el sistema.
IV. DERRIBAR LOS OBSTACULOS QUE IMPIDEN EL PROCESO JUSTO CONSTITUCIONAL ES EL RETO DE LA DECADA.

a) Si omitimos -o devaluamos- la significa. cidn decididamente obstruccionista y desvirtuadora de la concepción actual del proceso justo constitucional en razón de múltiples vallas $e$ inocultables efectos embarazosos, de estorbo y trabas -óbices, dice la Corte-, dejamos de hacer cierto el mandato de un proceso ncon todas las de la ley" $y$ continuaremos brindando sólo una justilicación aparente, de hueco garantismo formal, sin la encamadura suficiente y el rechazo de la gente. Lo desmiente dia a dia la critica que proviene de la sociedad.

El debido proceso legal, para muchisimas, no puede alumbrar, o no nació bien o, en su andar, desde el comienzo, quedó taponado para una de las partes, atascado por las dficulades insuperables que cemaron ol camino al acceso efectivo de la justicia or,

b) De alli que ei persamiento modemo en tomo del acuciante encuadramiento de tan sensible problematica se empeña, con obstinación, en tumbar las harreras -cullurales, econdricicas, de desigualaciòn matetial o format- que en la praxis destiguran y

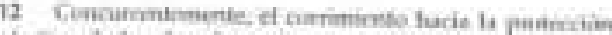

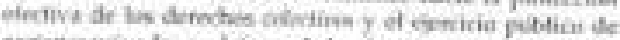

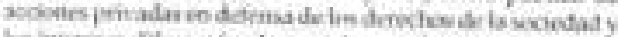

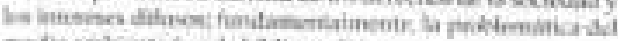

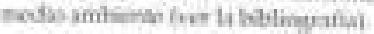


distorsionan el recreado y maduro mandato constitucional. Todos sabemos que, para inmensos bolsones de nuestra población, el acceso a la Justicia no es otra cosa que un Ifusorio propósito inalcanzable, sin miras de logro o materialización razonable cial,

Proseguir con las explicaciones -conceptualistas, de superticie, apegadas a la red de técnicas instrumentales- es persistir en una motivación insafisfactoria; incomprensibie; que genera resentimientos. y una fatiga en el ánimo que puede agudizarse en tiempo en que la velocidad de los cambios es asom. brosa.

Los operadores -fundamentalmente los jue. ces- cstán en patente certeza de ese inocultable relevamiento, de la actual crisis de la Justicia, y de que los buenos principios de la Ley Fundamental les imponen la pres. tación de un Servicio general sin discriminaciones ni reservas, Que, conno fal, debe incorporarse -interiorizarse- en la conciencia social, sin lo cual habra de perpetuarse la incredulidad o desconfianza en esa institución basal.

c) En la medida en que las señales $e$ indicadores concretos no traduzcan una enérgica tendencia de equiparaçión, de igualación, el cuadro no variara. Es impres. cindible que los hechas muestren el acorta. miento de los desniveles incompatibles con la eficiencia y calidad de un Servicio que a todas se ha de brindar con sujeción a un

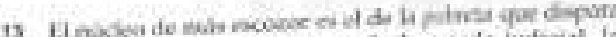

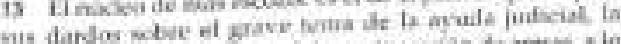

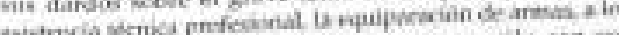

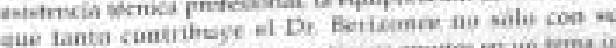

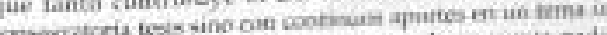

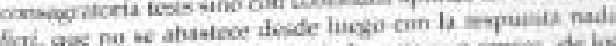

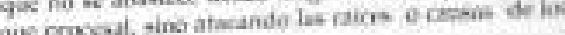
jmhlimissicials principio real de igualdad $-y$ al que todos tengan en verdad acceso efectivo-. Las buenas intenciones no se espejarán en las creencias del pueblo, porque en él está arraigada la honda sensación de que perdura le permanente disparidad de posibilidades con la ineludible consecuencia de que la mayor parte de nuestra población no liene manera de ejercer ef derecho constifucional a ha husticla.

Las ideas, pues, que como eje de las reflexiones y sostén de las propuestas enunciadas, recogen las inquietudes de un vasto pensamianto de recambio, cisconforme con el mantenimiento de una orientación que no se compadece con los dictados de las directivas de la Constitución, y con los valares y sentimientos que, en estas horas, anidan en el seno de todas las comunidades $-y$ la nuestra percibe profundamente-son la que avivan los entusiasmos para proseguir una empresa, por cierto inacabable, que debe desembocar en la construcción de un munde mejor.

Existe un tremendo desfase entre las normas y la realidad, y ello acontece en mo-mentos de nuevas tensiones y el acoso de conflictos de diterentes dimensiones porla insegunidad de una violencla cultural y social crecientes y frente al avance de la pobreza y la marginalidad (la Argentina secreta).

Polencial de conílictos de altos riesgos. Ello proveca una especial sensación de precariedad e insuficiencia de las saluciones que la Democracia debe ofrecer. Al no comesponderse la magnitud y complejidad de los problemas y la envergadura de las demandas con las respuestas que el sistema ofrece, pueden provocarse grietas en la adhesion al mismo; y dentro de el, la justicia se encuentra en un registro muy especial, 
cuya evolución y ajuste se ve atascado por diferencias tan excluyentes.

d) La Corte Suprema, en lo suyo (queremos decir en lo que cabe hacer como Poder) ayu. da, docididamente, a esa finalidad, y es de desear que su activismo -prudente pero también osado-no destallezca. Pero no es bastante. Las causas negativas son esencialmente externas al Servicio de la Justicia y ello requiere el empeno superador de todas

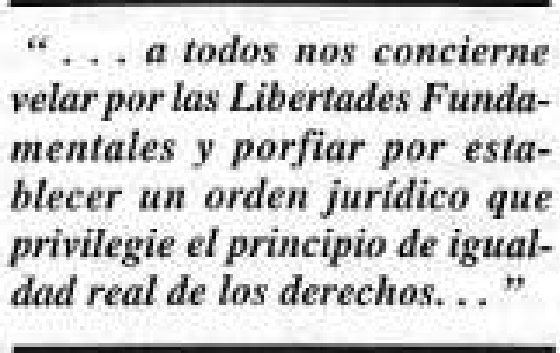

las áreas, porque las propuestas más adecuadas doben provenir no sblo del Estado sino, esencialmente, de la saciedad. Es que a todos nos concieme velar por las Libertadas Fundamentales y porfiar por establecer un orden juridico que priviegie el principio de igualdad real de los derechos, sin el cual no daramos un paso adelante en el terreno de la convivencia solidaria y justa.

e) Asimismo, habra que insistir en que la concepción del "proceso justo + debe ser inlegrai, sin fisuras, sin conceder nada a los abusos.

De alli que no deje de llamar la atención ea desenlace del caso del general Noriega que. aún tratándose de un personaje indefendtele, no legitims sentar la arbitranta tesis acogida por la Suprema Curte de la Unibo, segùn la cual su pais puede juzgar a presuntos delincuontes detenidos llegitimamente (vio- lando la soberania de Panamá) en otro, como sucedo en la causa asi juzgada.

El derecho internacional no admite la existencia de Estados que se atribuyen, per se, la función de valar por los derechos fundamentales y liderar la lucha antidroga, porque introduciria un desorden incompatible con el principio de la iguaidad de los derechos entre las naciones ${ }^{\text {ial! }}$

También ese nobstáculon de los paises poderosos y udominantes* en la imposición, por la tuerza, de los criterios de conveniencia, conspira contra el Modelo del proceso justo, que se asienta en un basamento sustancialmente opuesto, que no tolera tales discriminaciones irntantes, al abrir dudas acerca de la capacidad de los regimenes democráficos para dar respuestas a los verdaderos y cruciales problemas de todos los dias, que no toleran la actuación de avarcs criterios de solidaridad social.

1) ¿Como no reparar, además, en la gravitación de uno de esos *obstáculos*, los intereses establecidos más perturbadores, que habian venido operando en la penumbra, casi "invisiblemente", pero que, modemamente. van ganando rauda plaza conspicua y perceptible: los -lobbiesw in que presionan la independencia de los jueces?

g) La mención de los factores negativos facilmente se multiplica. Soblo ponemos de resalio algunos de ellos, además de los clasicos: pobreza, analfabetismo, desamparo técnico-profesional, el tiempo (demoras) y la onerosidad prohibitiva del servicio, entre

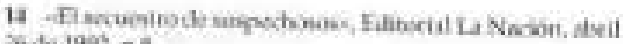
in de $1996, \mathrm{p}$ \&

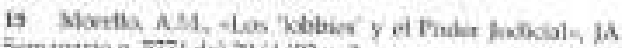

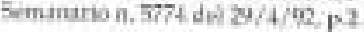


otros que no operan en plena luminosidad.

Es nitido que el arsenal tradicional - tanto de! derecho material como del procesal-es. cuanto menos insuficiente para regular esos fenómenos nuevos. Sus explicaciones para otra «materias -más estática, circunscripta, particularizada, que busca reparar, indernnizar, dar respuesta ahora a un problema, violación o daño acaecido en el ayer-otro objeto, otros scportes subjetivos y otros fines (en el presente, en rol fuertemente preventiva, en escala social) buscando las respuestas mats útiles para la paz en la convivencia y en retaciones de duración. Oue hacia adelante se van haciendo y proyectando con nuevas y complejas tensiones en el futuro. Las que están en uso son inocultablemente destasadas e impotentes para atrapar y conducir a la adecuada composición esa masa de nuevos tipos o familias de asuntos.

h) EDerecho procesal debe, por ande, trashgurarse, queremos decir, servir de otro modo, trasmudarse, en el sentido de no olvidar ni cancelar sus propias e históricas explicaciones, pero asumiendo las de racambio y adaptación, a tono con la nueva comple. jidad, dimensión y trascendencia social y de integración comunitaria que afloran en esas realidades que ya nos han invadido y respec-

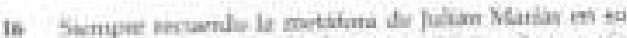

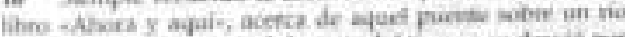

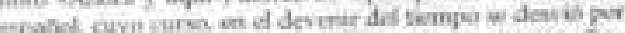

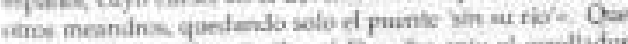

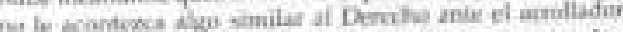

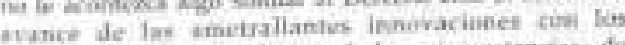

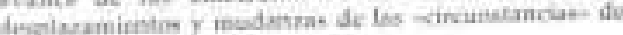
Dateyz
}

to de las cuales no puede cerrar los ojos, a riesgo de que su tratamiento se le escape de las manos, pasando a otras inéditas (16)

V. MIRANDO-ESPERANZADOSAL NUEVO MILENIO.

a) Hay, en verdad, una toma de posición global frente a la Vida y a fa Democracia. Privilegiar un modelo abierto, flexiblo, dinamico: mayores legitimaciones y participación activa; centrat en otro orden de pre. ferencia a los sujetos destinatarios del Derecho y la futela procesal efectiva: consumidores, usuarios, victimas. Visión funcional de las técricas de aplicación; nuevos métodos, alternativas y cpciones, resultados mas humanosy comprensibles; y metas más realistas, que sin bucles y excesos rituales, lleguen al pais del Derecho vivido, Es la brójula que guia el Proyecto y Modelo de Florencia.

Inocultable, también, es la juridización de la sociedad invadida por el Derecho, tanto como "la universalización de los valores de la libertad y la vida (en el sentido además de la dignidad y calidad do esta ùltima) en la modemidad, que son condiciones previss y a la vez consecuencia de la aparición de esas pretensiones realesque buscan su completa y efectiva realizacion- in. Ascensos.

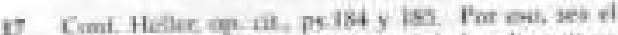

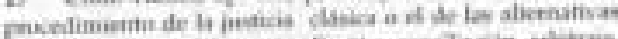

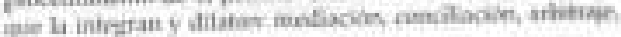


preferencias y adaptaciones que son consustanciales al hombre social ${ }^{(14}$.

El rumbo y las metas, por ende, estấn ya diagramadcs.

b) No son una utopia, un deseo frágil o una finalidad fútil o inconducente, huidiza. Somos optimistas, aunque no desconocernos que se ha afirmado que \&la justicia se convierte en un camaleón al revés: siempre asume olros colores distintos a los de su contorno. En el momento en que el entorno asimila su color. la prople Justicia lo cambia. Cazamos la Justicia sin apresarla. Corregimos injusticias particulares pero no alcan-zamos la justicia completa. La Justicia es un fantasma de diferentes formass. ¿Puede ser apresado un fantasma? ¿Es posible una sociedad justa?.. Descontado que ni el de la Sociedad ni el del Derecho son mundos absolutos, perfectos, inmodilicables.

Es más; - aun reconociendo que la sociedad justa es posible, todas como la presente no dejan de ser injustas porque la explotación, dominación y división del trabajo, no han experimentado una igualdad téctica (égalité de fact) $\approx$. Sin embargo, también se ha agregado con convicción y esperanza: La sociedad justa todsvia no ha sido posible, pero ahora sil to es, porque:

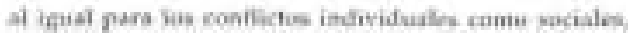

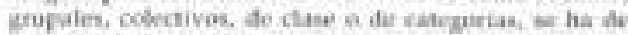

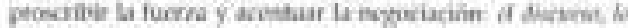

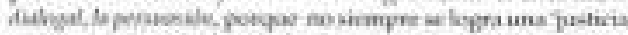

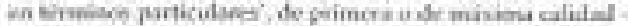

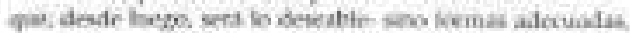

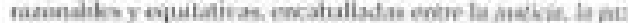

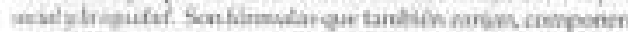

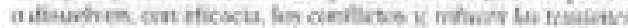
covoifraswirn

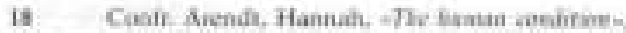

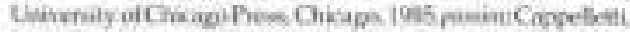

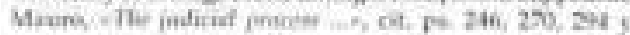
Hegentes
1) Debemos aceptar la wcaza de fantasma" como parte de nuestra condición humana. Siempre somos capaces de corregir aigunas injusticias. El progreso es fragmentario:

2) No es posible nil deseable una sociedad más allá de ta justicia. Ello asł porque una sociedad completamente justa no es deseable porque seria una saciedad en la que sólo se da el concepto estatico de justicia (พ),

c) Las expectativas de mejoras en lberoamérica se mueven a impulsos de un pensamiento único que revitatiza la protección de las Libertades Fundamentales, una de las cuales y por cierto de las más significativas es la de contar con que está asegurado un proceso judicial efectivo $y$ útil.

De lo que se trata, al cabo, es de acelerar el pasaje del tormal Estado de Derecho al Estado de Justiciar de alls que la empresa no puede estar por debajo de la sociedad, como apuntó agudamente el monarca español don Juan Carlos; queremcs decir, de la preocupación más importante que ella tiene al respecto. Entonces, debemos aplicar lo mejor de nuestras energias en miras de reducir y eliminar los nobstáculos: que desde adentro del proceso judicial y las más de las veces y con una gravedad menoscabante. desde afuera de el, impiden o postergan, en las hechos, la superación del estado actual de cosas.

Nada mejor que alistarnos a esos fines y

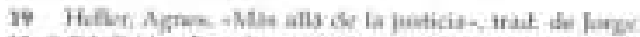

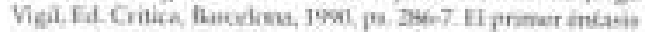
nos pertrocese La dotora dice wr fansciense de las.

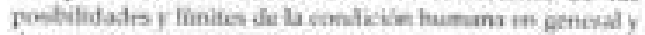

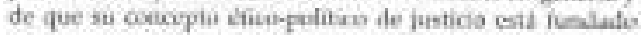

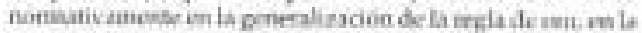

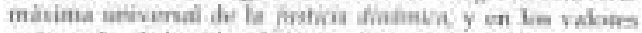

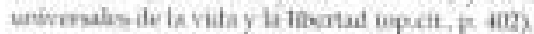


poner manos a la obra. Será la mejor contribución al Quinto Centenario del Descubrimiento de las Américas, ouyo destino. según el gran humanista dominicano Pedro Henriquez Urenta, en una fecunda integración, es el de ser, precisamente, la Patria de la Justicia.

d) Si achicamos los obstáculos -las barreras- (sabiendo que emergerain otros) la igualdad de oportunidad para conlactarse realmente con la Justicia la habremos aproximado en los hochos. $\mathrm{Y}$ esa mela -que no puede ser torcida por una opinión pública descreida- de por si vale los estuerzos. EI sentido y el sentimiento de la justicia en el mundo de fin de siglo, no pueden dejar de llevar ese norte (a).

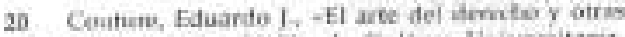
encotitacionea-, Fundaciein de Cuttura Inwersitaria

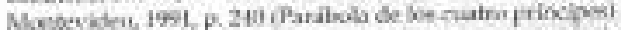

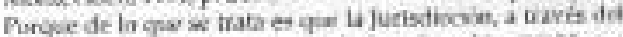

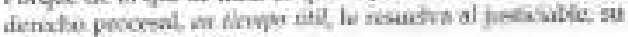
inarase problems cancieto

\section{BIBLIOGRAFIA.}

A.A.V.V. "Derecho y Realidads. Ed. Academia de Derecho y Ciencias Sociales de Buenos Aires, 1990.

Aparicio, C., =Inlome sobre la administración de Justicia en los EE.UU. de América", Rev. Fac. de Der. y Cs. Sociales, Montevideo, Uruguay, 1986 (ns. 1-2) p. 135.

Arruda, Alvim M., "Anotaçóes sobre as perpexidedes $\theta$ os camintios do processo ciwl confemporaneo. Sua evoluçáo so lado da do direito materialo, "Direito do Consumidor", Rev. dos Tribunais, San Pablo, n.2 (1992), ps. $76 \cdot 99$.

Barbosa Moreira, J.C., "Tendencias contemporáneas do Direito Processual Civil". Ed. Saraiva, San Pablo, 1984.

"A funç̧âo socialdo processo civil modemo", Rev. Brasil Dir. Proc. 1986 (v.49), p.54.

"Os temas fundamentais do direilo brasileiro nos ancis 80. Direito Processual civilu, Temas de Direito Processual, Ed. Saraiva, 4a, serie, 1999 . p.1.

- Açes coletivas na Constitulçá Federal de 1988s, Rev, de Processo, San Pablo, ก.61 (1991), p.187,

Berizcnce, Roberto O., "Efectivo acceso a la dusticia", Ed. Platense, 1987.

*Medios para aumentar la eficacia del servicio de justicas", Informe General a las XI Jornadas Interamericanas de Derecho Procesal (Rio de Janeiro). 1988.

-Evaluación provisional de una investigación empiricaw, ED 114-860. 
-Aigunos obstáculos al accesp a la Justician, Comunicacion al "Coloquio sobre la Administración de Justicia de lberoamérica: (a celebrarse en México, agosto de 1992).

Calmon de Passos, J.J. .O probiema do acceso a justica no Brasith, Fiev. de Processo, San Pablo, n.39 (1985), p.78

Calamandrei, P., "Proceso y Democracia”, traducción de H. Fix Zamudio, Ejea, Bs.As, 1960.

Cappelletti, M., "Proceso, ideologias. sociedado, traducción S. Sentis Melendo y T.A. Banzhat, Ejea, Bs.As., 1974.

* Acceso a la Justicia (Como programa de relormas y método de pensamiento) *, traducción de G. Seminara, Revista del Colegio de Abogados La Plata, 1981 (n.41), p. 159.

"Algunas reflexiones sobre el rol de las estudios procesales en la actualidad *; traducción de P. Bermejo, Jus, La Plata, n.39 $\{1988\}$, p. 12 .

- Canstitucianafismo modemo e o papel do Poder Judictario na sociedade contempo. rainaan, Pevista do Processo, San Pablo, n. 60 (1990), p. 110.

*O Acosso a unstiça e a funçalo do jurista em nas sa época", Povista de Processo, San Pablo, n.61 (1991), p. 144

"The judicial process in comparative perspectiven, Clarendon Press, Oxford, 1989.

Cappelletti, M. y Garth, B. "El acceso a la Justician, La Plata (Ed. Colegio de Abogados). 1983, traducción de S. Amaral,
Cindra, A.C., de A., Pellegrini Grinover, A. y Dinamarco, C.R., - Teoria geral do Processos, Ed. Rev, dos Tribunais, 8a. ed., San Pablo, 1991 , p. 35.

Constitución Politica de Colombia (1991).

Denti, V., * Un progetto per ia giustizia civlew, II Mulino, Bologna, 1982.

Gelei Bidart, A., "De derechos, deberes y garantias del hombre comûn*, F.C.U., Montevideo, 1987.

Gritlith, J.A.G. "The politics of the judiclary", 4a., Ed. Fontana Press, London, 1991.

Heller, A. -Màs allé de la Justicia*, trad. de J. Vigel, Ed Critica, Barcelona, 1990.

Landoni Sosa, A., wa justicia de menor cuantia y la reforma procesali, Rev. Uruguaya de Der,Procesal, 1987 (n.1), p.60.

Lozano-Higuero Pinto, M., "Cambio social, socialización y privatización de la justicia". "Justicia B8*, Libreria Bosch, Barcelona, 1988, p.570.

Martinez, $\mathrm{O}$ d., "El acceso a la justicia. Protección privilegieda de los derechos y procesos de menar cuantia", ED 113-903.

Morello, A,M., «El abogado, el juez y la reforma del Codigo Civils, Platense, 1969.

-Contrato y proceso. Aporturas", PlatenseAbeledo Perrot, 1990.

- La reforma de la Justician, PlatenseAbeledo Perrot, 1991

"La prueba. Tendencias modemas", Platense-Abeledo Perrot, 1991. 
"Alocución de cierre en el XVI Congreso Nacional de Derecho Procesal argentinon, 1991 (LL Actualidad 26/11/91).

"La Responsabilidad civil de los profesionales, la defensa de la sociedad y la tutela procesal efectiva", en el Libro en "Homenaje. al profesor Dr. Luis Andornos. Platense, 1992.

"Los 'lobbies' y el Poder Judiciain, JA semanario n. 5774 del 29/4/92, p.2.

-La Corte Suprema en acción", PlatenseAbeledo Perrot, 1989, ps. 11.53 (La justicia de acompanamiento).

-El conocimiento de los derechos como presupuesto de la participación", ED 124942.

"El arreglo de las disputas sin llegar a una sentencia final (El Tribunal de Pequenas Causas de Brasil)". JA 1985-III-743.

Morello, A.M-Hitters, J.C - Berizonce, R.O. y Nogueira, J.C., \&La Justicia entre dos epocas*, Platense, 1983.

Morello, A.M. y Berizonce, A.O., "Las entidades profesionales y los desafios del presenten, JA 1984-11-665.

Morello, A.M. y Stiglitz, G., "Tutela procesal de derechos personalisimos». Platense, 1986.

Morello, A.M. y Morello, G.C., "Libertades fundamentales y ética (Dialogo entre médicos y abogados)n, Platense, 1992.

Pellegrini Grinover, A, "Novas tendéncias do Direito Processualo, Forense Universitaria, Rio de Janeiro, 1990.
Seabra Fagundes, M., "A crise do Pader fudiciano", Fevista de Processo, San Pablo, ก. $60(1990)$, p. 118.

Sosa, G. L., La dimensión social y el acceso a la justician, JA 1984-III-829.

Watanabe, K. *Acceso a la Justiça e socie. dade modema", en (autores varios), "Participacalo e processco, ed. Revista dos Tribunais, San Pablo, 1988, p. 128.

White, G.E., "Eart Warren (A public life)"s, Oxford, University Press, New York, 1987. 